\title{
Using Computer Assisted Language Learning In TeachingEnglish Language at Elementary Schools in Gaza Governorate
}

\author{
Dr. Ahmed Maher Mahmoud Al Nakhal
}

\begin{abstract}
The study aims at exploring the effect of Using Computer Assisted Language Learning in Teaching English Language at Elementary Schools in Gaza Governorate. The study is about using such technology in teaching English language. The study also shows that teaching will be better by using Such technology. The research deals with computer. Such study also aims to improve teacher's using of computer in teaching process and to find out the influence and impact of such set and technology in teaching English Language at elementary stage schools. The importance of such study lies in its drawing the attention of teachers, officials and the concerned parties for using computer in teaching process. Such study carried out and applied in the first term of the scholastic year 2007/2008 at elementary stage schools in Gaza Governorate. The researcher used descriptive analytical method. After analyzing the results the researcher found that "Listening "occupied the first rank ,"Reading" occupied the second rank in teachers' evaluating their performance in English language skills. There are grate differences between male and female teachers in using computer in teaching English Language . There are statistical significant differences refer to gender variable, such differences were in favor of female teachers. The researcher adopted some recommendations and suggestions to enhance and encourage using such sets and appliances in teaching process.
\end{abstract}

\section{INTRODUCTION}

With the development of user-friendly computers and software and the rapid reduction in their prices in the last decade, the use of computers has become widespread and has expanded in homes, offices, and schools. In the 21 st century, everyone is required to use computers to some extent to function in our society. ( Takako Kawaba July 2006 ). Computer technology has become an integral part of the teaching and learning process (Mitra, 2000). The use of computers has permeated education from the kindergarten level to post-graduate studies (Mitra, 2000), including the context of foreign language instruction (Chapelle, 2001). Many university-level foreign language programs currently utilize computer technology in their curricula, and foreign language educators are seeking ways in which technology can enhance and improve how they do their job (Bush, 1997). Language is at the center of human life. People exchange ideas and experiences through language. The acquisition of communication skills in one's first language is a life long process, but the basic skills are acquired quite early in life. When starting school children are already conversant in their mother tongue. Therefore, language teaching aims to enable them to use language effectively and appropriately in various social and cultural contexts, consequently teaching focuses on "language for/as communication". Applied linguists such as Lightbown and Spada (1989) have found that language learning is promoted effectively in a non-naturalistic environment like the classroom. However, other linguists such as Krashen (1982) and Charalambopoulos (1997) point out that classroom language learning cannot easily overcome limitations such as the lack of authenticity that affects learners' motivation to interact and practice language in the same environment as in natural settings. More precisely, learners meet many more difficulties when having to produce written speech. Producing a successful written text for a particular audience and a particular purpose is a complex task for them and they often fail to accommodate the absent recipient-reader of their texts. In order to overcome classroom teaching limitations, Yalden (1987) argues that the description of the learner profile should be taken into account, because the syllabus design and the development will then be better tailored to the needs identified. In addition Hubbard (1992) considers learner variables to be a major factor for the design and development of CALL courseware.( Marie-Josee Hamel-1995). Computer-assisted language learning (CALL) came of age in the early 1960s (Kern \& Warschauer, 2000).

However, it was only in 2004 that the Chinese Ministry of Education (MOE), for the first time, formally highlighted the role of the computer and networking in its revised College English Teaching Syllabus (CETS) which would be the guide for English teaching in mainland China. This article reviewed the CALL literature and identified some common concerns surrounding the early implementation of the CALL. The article is anticipated to provide a firmer basis for governmental policy decisions about the use of CALL, to give CALL teachers and learners a better understanding about the theory and practice of CALL and ultimately to enhance the overall quality of English language teaching and learning in Chinese universities. 


\section{The Problem of Study}

The researcher discusses using computer assisted language (CALL) in teaching English Language at Elementary Schools in Gaza Governorate .The study will answer the main question :What are the effects of CALL using on students who study English at Elementary schools?

The following sub-questions arise from the main question :-

1 How do teachers evaluate their performance in English language skills?

2-How do teachers evaluate the learners standard in English Language skills ?

3-How are the effectiveness of activity skills of English language learning?

4 Are there any statistical significant differences at $(\propto \leq 0.05)$ in the level of application of activity skills in Gaza

City based on gender suggestion?

\section{The importance of the study}

The researcher noticed during his career and teaching English as a foreign and second language that computer plays an important role in teaching English .The importance of study lies in the following points:

1-The research formulate a list of useful techniques and procedures for TEFL by using CALL.

2-The study will upgrade the level of English language teacher by using CALL.

3-The research shall draw the attention of the persons in charge and the officials to the importance of providing suitable environment and financial requirements to improve English language teaching by using CALL.

4-The study will draw the attention of persons in charge and the officials to the importance of teacher's role in achieving and carrying out effective English Language teaching by CALL.

\section{The Objective of the Research}

The main objectives of using CALL system in the elementary schools are:-

- Improving teaching and learning by using a computer as tool that may enrich the existing teaching practices and opening new methods for presenting linguistic information and knowledge.

- Promoting self-determination learning instrument that can be used collectively at school as well as individually at home.

- Increasing the motivation by supporting a decision making and problem solving activity.

- Assisting the children to acquire a certain degree of computer literacy. Such knowledge may be a valuable ingredient in order to over come the demands of their life.

- Introducing basic features of information technology.

- Creating a great individual freedom and breaking down the rigid and standardized classroom practices.

- Encouraging the students to realize and acquaint with the role and importance of computer and the applications of computer.

- Pre-qualifying the students to live with new technology development and computer.

- Developing of students' mental skills by using computers.

\section{LimitationsoftheStudy}

The study has three limitations :-

1-Limitation of time

Thestudywillbeappliedinthefirsttermofthescholasticyear2011/2012.

2-Limitation of place

The study will be carried out in Gaza Governorate Elementary schools-Subject Limitation

The study will deal with and study using computer assisted language learning In teaching English Language at Elementary Schools in Gaza Governorate.

\section{DefinitionofTerms}

CALL:Computer Assisted Languag eLearning EFL: English Foreign Language T EFL : Teaching English ForeignLanguage

\section{PreviousStudies}

Many researches dealt and studied using computer assisted language learning In teaching English Language . John L.D.Claek(1988) in his research "Toward a Research and Development Strategy for CALL" describes and recommends an approach to CALL. He discussed eight major procedural steps for developing, refining and evaluating the efficiency and effectiveness of language teaching programs based on the input-process outpot model describe. The research of Dominique A.M.Y. Abrioux (1989) was about "CALL and distance Education." Such study analyzes the application second language teaching at distance. It also introduces specific ways of CALL to remedy some difficulties that face second language. MariaTzevelekov Chondroyanni and Stefanos Paschails(2001) paper is about "CALL, A Multimedia Interactive Environment for Teaching Greek as a second 
language." It aims to give an overview of the process of introducing educational technology into the minority schools of Thrace and to present the process of constructing a computer system for teaching Greek as a second language. The research argues the principles of assisted learning system (CALL). The study "Computer Assisted Language Learning(CALL) in China: Some common Concerns." Of LIU Meng, HUO Hong (2007) reviews the CALL literature and identifies some common concerns for CALL initiative. It finally points out the directions for better delivery of CALL in Chinese Universities. Stephan Bax (2002) in his paper "CALL-Past, Present and Future offers a critical examination and reassessment of the History of CALL, and argues for three categories : Restricted, open and Integrated CALL .It offers definitions and description of the three approaches and argues that they allow a more detailed analysis of institutions and classrooms than earlier analysis. It is suggested that we are currently using the second approach, Open CALL , but that our aim should be to attain a state of normalization in which the technology is invisible and truly integrate. This state is defined and discussed. In the final section, the paper proposes some ways in which this normalization can be -using ethnographic assessments and action research for example- thus setting an agenda for CALL practice in future. The study of Ahmed Al-Zeer(2005) aims at distinguishing the effect of using computer in the achievement of basic and secondary grade students from computer teachers view in Salfeet District in the scholastic year 2004/2005. The researcher adopted three hypothesis at the level $(\mathrm{a}=0.05)$. The researcher adopted some recommendations in order to encourage using the computers in such levels .

\section{COMMENTS}

In comparison with the studies carried out on using computer assisted language learning in teaching English Language at elementary schools in Gaza Governorate, they do not have and include many studies on the advantages and disadvantages of using CALL. The majority of these studies pointed at and focused on the CALL in general without mentioning the influence and effect of the same on learning and teaching English language. The research is distinguished from the other previous studies that it provides a brief account on the new possibilities that CALL may supply the English language. The research presents a general changes that

CALLmayintroduce.Suchresearchshowsthefollowings :-

1-Advantages and disadvantages of using the CALL.

2-The technical requirements for using CALL.

3-The programs that necessary for CALL.

4-Analysis of stages of methodology related to CALL.

5-Methodology of teaching English language skills by using CALL.

\section{The Method of Study}

The researcher will follow the analytical descriptive method in this study.

\section{A-Population}

The population of study is from English teachers at the elementary schools in Gaza for the scholastic year $2015 / 2016$.

\section{B-Sample of Study}

The researcher will choose a random sample from the population of study composed of (46) teachers who teaches English Language.

\section{C-The instrument of Study}

The researcher will design a questionnaire composed of two parts.

\section{TheValidityofthequestionnaire \\ 1-Agreement of referees}

The questionnaire was introduced for a group of specialized linguistics university tutors and lecturers at Gaza Governorate. They provided their recommendations and suggestions about the validity of the items of the questionnaire. The researcher amended and modified the same upon the suggestion and recommendations of the referees.

\section{The Stability and Reliability of questionnaire Internal Consistency}

The stability of the questionnaire was estimated by using Person method. The coefficient correlation of each item is (0.01) and (0.05). The questionnaire is proved to be reliable. Alpha Cronbach coefficient is (o.524) and the splithalf coefficient is $(0.676)$ such thing indicates that the questionnaire can be applied in the study. This indicates that 
the questionnaire is highly enjoyed with high stability and liability which may give the researcher confidenceoapplythesameonthesubjectsofstudy.

\section{COMPUTER ASSISTED LANGUAGE LEARNING}

Compute-assisted language learning(CALL) is an approach to teaching and learning foreign languages where the computer-based resources such as the Internet are used to present, reinforce and assess material to be learned .It usually includes a substantial interactive element. It also includes the search for and the investigation of application in language teaching and learning.(1)Except for self-study software, CALL is meant to supplement face-to-face language instruction, not replace it(2) CALL, has also been known by several other terms such as technology-enhanced language learning(TELL), Computer-assisted language instruction(CALI)and computeraided language learning but the field is the same.(3) Levy defines computer-assisted language learning (CALL) as $"$ the search for and study of application of the computer in language teaching and learning"(1997:1) In the recent history of language teaching, there have been major theoretical movements, namely, the structural , the cognitive and the socio-cognitive, all of which have greatly influenced CALL development. CALL development over the past 30 years are accordingly categorized into three distinct phrases : structural CALL, communicative CALL and integrative CALL respectively (Kern\&Warschauer,2000).

The technologies used in CALL instructions generally fall into two categories, software and internetbased activities.Software used in CALL environment can be designed specifically for foreign/second language learning or adapted for this purpose. Most language textbook publishers offer educational software of some sort, whether it is meant to support a paper textbook or to stand alone for self-study.(4) Most programs designed for language learning are tutorials. These generally are drill programs that consist of a brief introduction plus a series of questions to which the learner responds and then the computer gives some kind of feedback. Programs not designed specifically for language learning can be adapted for this purpose. Authoring programs allow an instructor to program part or all of the content to be learned and program part or all of how the content is to be learned.Internet activities vary considerably ,from online versions of software(where the learner interacts with networked computer),to computer-mediated communication (where the learner interacts with other people via the computer),to applications that combine these two elements. Nowadays, websites that cater to foreign-language learners ,especially those learning English are so numerous and varied that it can be very difficult to determine where to begin.(5) Many of these websites are based on the drill exercise format but some also include games such as Hangman.(1)CALL's origins and development trace back to the 1960's (Delcloque 2000). Since the early days CALL has developed into symbiotic relationship between the development of technology and pedagogy. Warschauer(1996) divided the development of CALL into three phases: Behavioristic CALL, Communicative CALL and Integrative CALL (Multimedia and the Internet)8. Bax (2003) perceived the three phases as Restricted, Open and Integrated.

Bahavioristic CALL is defined by the then-dominant behavioristic theories of learning of Skinner as well as the technological limitations of computers from the 1960's to the early 1980's. Up to the late 1970's, CALL was confined to universities where programs were developed on big mainframe computers .

Communicative CALL is based on the communicative approach that became prominent in the late 1970's and 1980 's . The history of CALL has been divided into two periods :-

a) Beginning of CALL (1960's \& 1970's): Large-framed computers were used and CALL appeared only in the form of experimental projects carried out by universities, i)The Stanford project:Patrick Suppes developed computer-assisted instruction(CAI) at Stanford University in the 1960's and designed software with feedback, lesson branching and student record keeping.

In communicative approach the focus is on using the language rather than analysis of the language ,teaching grammar implicitly .It also allowed for originality and flexibility in student output of language. Multimedia programs, listening is combined with seeing, just like in the real world. Students also control the pace and path of the interaction. ii) The PLATO Project: PLATO( Programmed Logic for Automated Teaching Operations) was carried out by the University of Illinois in 1960 . It was a project with considerably substantial funding and was used to teach a variety of subjects including foreign languages. It was tutorial system that consisted of a central computer and terminal providing access to a large number of students and enabling users to communicate through "notes files" that resembled today's e-mail system. The mode of instruction was rather mechanical as it consisted mostly of repetitive language drills(drill-and -practice ), grammatical explanations and translation tests( Warschauer, M.,\&Healey ,D, 1998;Levy.M.,1997) iii) The TICCIT Project: It began in the early1970s at Brigham Young University (Timed-Shared Interactive Computer Controlled Information Television), which combined television ,graphics and testing. The particular characteristic of the project was that teachers could not intervene in the teaching method employed as "TICCIT" had its own in-built instructional system" (Levy 1997)but could not make decisions over the material used. Another major fault of TICCIT was the fact that it provided inadequate feedback to students and also that students tended to feel isolated. 
b)Recent CALL: The advent of the microcomputer in the early1980s revolutionized the area of CALL, as millions of teachers and students could easily gain access to computers, either at work or at home and, subsequently ,to educational programs accompanying them (Ahmed et al ,1985).

i)Programming languages: With compilation of programming languages such as BASIC and PASCAL , language teachers who possess the motivation and programming abilities ,can write CALL programmes (Levy,1997);Kenning \& Kenning 1990). These languages, also known as high level languages (Ahmed et al,1985), although difficult, are not impossible for non-specialists to use because they employ English commands(print, input, etc.) as opposed to other machine-code language ( low-level languages) that incomprehensible to nonexpert(Jones \& Fortescue, 1987) .

ii-Authoring toolsFor teachers who are interested in developing their own multimedia programs ,there are software authoring tools such as CALIS, Hypercard, Toolbook,Hyperstudio, Supercard, Toolbook and Macromedia Director, which offer the opportunity to create language instructions programs that include a variety of media (text, graphic, sound, animation, and video) and hypermedia ,at the same time, as "the multimedia resources are all linked together and learners can navigate their own path simply by pointing and clicking a mouse." (Warschauer,1996)

iii-Authoring PackagesAs language teachers often find it difficult to use programming languages or authoring tools, there is also the alternative of authoring packages that make the task for the non-specialist programmer easier, as they do not presuppose knowledge of an authoring code (Kenning\&Kenning 1983). In such packages, teachers can use their own material for a range of activities that are pre-determined by the program. The aim is to let the teacher concentrate on the demanding task of creating successful and pedagogically sound lessons, while the computer can deal with the technical aspects and the delivery of the lesson through its programming. Very popular examples of such programs are the following that are included in Wida's Authoring suite :

-Storyboard: text reconstruction program where the text is entered by the teacher, and learners rebuild it by guessing words.

-Match master: matching pairs, ranging from single words to short paragraphs.

-Choice master : Multiple choice activities .

-Test master :a question and answer program .

-Gap master : texts containing up to 200 gaps, each with several alternative correct answers, as well as hints.

-Pinpoint: matching a title to a text that contains gaps.

-Vocabulary : Vocabulary exercises through six games ( Word Order, Anagrams, Alphagame, Skulman, Mindword, Which word.)

iv-Ready-made software A large number of software packages have been designed ,mostly in the form of CDROMs, for language instructions, which can be easily used without requiring considerable knowledge of using computers. The problem arises when selecting the appropriate software as the teachers should evaluate the materials very carefully in order to choose the one or ones that would have pedagogic value and best suit their students' needs. Nevertheless, even if the software is very carefully designed, it is very unlikely that it would entirely meet the specific needs of one's pupils (Kenning \&Kenning 1990).

v- The InternetThe first form of the internet as Computer-ediated communication(CMC), appeared in the 1960s, but only in the last ten years did it take huge dimensions and drastically invade many aspects of our lives. The internet is a network that encompasses thousands of smaller computer networks that are located throughout the world. The impact of the internet on EFL teaching has also become every significant and is constantly increasing. The two most popular uses of the Internet for language teaching are the World Wide Web and electronic mail (email) (Kiraki Spaniu 2007).

\section{THE WORLD-WIDE WEB}

Abroad definition of the World-Wide Web could be that it is a vas area of hypermedia information that can be universally accessed electronically. Due to the huge amount information it encompasses and the diversity of the media it incorporates (text, images, sound),the World-Wide Web constitutes "perhaps the most exciting Internet application in the use today" (Warschauer,1996:402). The Web offers an abundance of authentic materials that can be exploited for EFL learning through various activities ranging texts on the Web and carrying out tasks based on them to creating web pages, either independently or in groups .

The e-mail is an application of the internet that can be defined as a form of asynchronous computermediated communication. It can be used very constructively in EFL learning as it can provide students with an excellent means of developing their writing skills. It can promote authentic communication as students can exchange written messages about various subjects with other learners of the language (Kiraki Spaniu 2007).As 
Ahmad et al. (1985:27) states," CALL arose from the combination of two separate factors: educational needs and technological means". Therefore, apart from the technological changes that have taken place in the field of CALL, It is essential that pedagogical issues relate to the area be also carefully examined, so that the educational needs are met to the maximum extent.Computers have long been considered as appropriate tools merely for repetitive language activities(e.g. grammar exercises) that did not require a high degree of interaction, giving teachers the time to carry out more stimulating activities (Higgins,1986:34). Gradually, with the development of more sophisticated programs and the advent of a more communicative pedagogical approach, computers acquired a more active and essential role in EFL teaching. According to Warschauer \& Healey (1998), CALL Methodology has been greatly influenced, throughout its history, by the overall methodology that has characterized EFL teaching at various points of its development. Warschauer (1996) identifies three stages that characterize the development of CALL over the last 30 years: Behavioristic CALL, Communicative CALL, and integrative CALL. The transition from one stage to the other did not take place abruptly and each stage retained some of the characteristics of the previous one.

\section{BEHAVIOURISTIC APPROACH}

This first stage of CALL, which was popular in the 1960s and early 19970s, was based on the dominant behaviourist theories of learning of that period. This behaviouristic model was actually based on Skinner's theory, which asserted that if a specific behaviour is rewarded, it is bound to happen again. Following that model, early computer programs focused mainly on repetitive language exercises with "true or false" type of feedback ,rewarding the correct answers with congratulatory comments. In that way, a lot of the emphasis was placed on "the relationship between a stimulus and a response" (Jones \&Mercer,1993:13). According to that theory, positive reinforcement for correct behaviour and negative reinforcement for incorrect behaviour lead to automatic acquisition of the language (Hubbard,1987). The drawback, as Wyatt (1987):86) mentions, was that "this early CALL software was of the drill-and-practice variety", capable of presenting " mechanical language drills" but unable " to handle open-ended student responses" and provide learners with some flexibility in the learning process.

\section{COMMUNICATIVE APPROACH}

The second phase of the CALL was based on the communicative approach,

which became prominent in the1970s and 1980s. Advocates of this approach asserted that teaching should be more concerned with authentic communication rather than mechanical tasks, rejecting, thus, the behaviouristic approach that applied until that time. Underwood (1984) has listed a series of advantages of using the communicative approach in computer-assisted instruction :

- Focuses more on using forms rather than on the forms themselves.

- Teaches grammar implicitly rather than explicitly.

- Allows and encourages students to generate original utterances .

- Does not judge and evaluate everything the students do.

- Avoids telling students they are wrong and is flexible to a variety of students responses.

- Uses the target language exclusively and create an environmental in which using the target language feels natural, both on and off the screen;

Gradually ,the communicative eapproa chceased to constitute the perfect learning situation, as teachers and program developers began to explore ways to integrate all skills in their teaching rather than focusing on isolated exercises, creating in this way a more authentic teaching environment. The answer to that need was the development of multimedia, which offered the ability to create mor comprehensive lessons .

\section{INTEGRATIVE APPROACH : MULTIMEDIA}

The most recent development in the field of CALL has been the design of multimedia programs since the early 1990s. Those programs, developed on CD-ROMs, combine a variety of media (text, sound, graphics, video and animation ) that can be linked together in order to convey a stimulating learning environment in which all four skills are integrated. The combination of the above-mentioned media "may facilitate greater comprehension of input than input which is delivered only via one of these modes" (Bert,1998:181). Such programs also favour autonomous language learning as they are non-linear and students can follow links that enable them to access different types of information and activities at their own pace, "making choices according to their own needs, learning styles and strategies"(ibid: 1982).

\section{COMBINATION OF THE THREE STAGES}

Each of the above mentioned stages theoretically represents a distinct methodological framework but in practice those stages may well be interconnected.Although the current trend of CALL focuses on multimedia, techniques that are derived mainly from the communicative approach and to a lesser extent from the behaviouristic 
approach may also be incorporated . The success of each approach depends on the way it is actually put in use . For example, even a drill-and-practice exercise, which is a typical behaviouristic activity ,can be more effective if carried out by students working in pairs.(Kiraki Spanou 2007).

\section{THE ROLE OF CALL IN TODAY'S CLASSROOM}

The importance that teachers place on the use of computers in EFL teaching varies ,primarily depending on their familiarity with the medium .For example, there are CALL specialists that consider computer-based instruction as a revolutionary teaching method that constitutes a panacea in the teaching field while others simply consider it as an extra component of the lesson that comes to supplement their traditional teaching practice. At the other extreme, there are a large number of teachers that are skeptical about incorporating computers in their class curriculum and see no real benefit emerging from this new practice. The latter are usually characterized by a certain degree of technophobia, which makes them believe that computers bring more complications than benefits to the EFL classroom.(Kiraki Spanou, 2007).A framework that can specify the role of CALL in the teaching process has originally been proposed by Taylor (1980), who asserts that the computer can assume three different roles, namely those of a tutor, a tool and a tutee. Levy(1997) elaborated on this framework focusing mainly on the roles of tutor and tool ,or what he calls "tutor-tool framework".In the tutor role, as the term denotes, the computer attempts to take over the role of the teacher, which makes it deal for self-access learning or, generally, whenever the presence of the teacher is not available. As a result, the computer takes on the difficult task of providing the learner with the right kind of guidance, feedback and help when required acco9rding to the methodology that was followed when the program was originally designed.

In the tool role ,the computer provides the learner with applications such as word processors or electronic mail that can be used to enhance learning without constituting a complete learning program per se. As opposed to the tutor role "the human is in direct control of the tool" Levy $(1997 ; 208)$, that is , the teacher provides all the guidance and the feedback that is required and the learner has to learn how to use the effectively. Whether a computer assumes the role of the tutor or a tool depends, firstly, on the way the teacher chooses to use it in the classroom and ,secondly, on the way the program designed .

CALL and computational linguistics are separate but somewhat interdependent fields of study. The basic goal of computational linguistics is to "teach" computers to generate and comprehend grammatically-acceptable sentences... for purposes of translation and direct communication with computers where the computer understands and generates natural language. Computational linguistics takes the principles of theoretical linguistics with the aim of characterizing a language with computational applications in mind(Hacken,2007).

A very simple example of computers understanding natural language in relation to second language learning is vocabulary drill exercises. The computer prompts the learner with a word on either the L1 or target language and the student responds with the corresponding word. The computer "understands" the input word by comparing it with a stored answer and gives feedback to the user. Cloze tests work on a similar principle, where the computer compares the words/phrases provided by the learner to a database of correct answers(Hacken,2007). On a superficial level, the core issue for humans and computers using language is the same; finding the best match between a given speech sound and it corresponding word string, then generating the correct and appropriate response. However, humans and machines process speech in fundamentally different ways. Humans use complex cognitive processes, taking into account variables such as social situations and rules while speech for a computer is simply a series of digital values to generate and parse language(Hacken,2007) (Farzad \& Knodt 1998). For this reason, those involved in CALL from a computational linguistics perspective tend to be more optimistic about a computer's ability to do error analysis and other pedagogical tasks than those who come into CALL via language teaching (Graham 2007).

The term Human Language Technologies is often used to describe some aspects of computational linguistics, having replaced the former term Language Engineering. There has been an upsurge of work in this area in recent years, especially with regard to machine translation and speech synthesis and speech analysis. The professional associations EUROCALL (Europe) and CALICO (USA) have special interest groups (SIGs), respectively devoted to Natural Language Processing (NLP) and Intelligent CALL (ICALL).

\section{THEORETICAL BASIS FOR CALL INSTRUCTION DESIGN}

Computers have become so widespread in schools and homes and their uses have expanded so dramatically that the majority of language teachers now think about the implications. Technology brings about changes in the teaching methodologies of foreign language unless they are used simply to automate fill-in-the-gap exercises (Noemi2007) .The use of the computer in and of itself does not constitute a teaching method, but rather the computer forces pedagogy to think in new ways to exploit the computers benefits and work around its limitations (Mark 2008) . To exploit computers' potential we need language teaching specialists who can promote a complementary relationship between computer technology and appropriate pedagogic programs (Noemi2007). 
A number of pedagogical approaches have developed in the computer age, including the communicative and integrative/experimentative approaches outlined above in the History of CALL. Others include constructivism, whole language theory and sociocultural theory although they are not exclusively theories of language learning. With constructivism, students are active participants in a task in which they "construct" new knowledge based on experience in order to incorporate new ideas into their already-established schema of knowledge. Whole language theory postulates that language learning (either native or second language) moves from the whole to the part; rather than building sub-skills like grammar to lead toward higher abilities like reading comprehension, whole language insists the opposite is the way we really learn to use language. Students learn grammar and other subskills by making intelligent guesses bases on the input they have experienced. It also promotes that the four skills (reading, writing, listening and speaking) are interrelated (Jonita 2002). Sociocultural theory states that learning is a process of becoming part of a desired community and learning that communities rules of behavior (Mitchell \& Myles 1998). What most of these approaches have in common is taking the central focus away from the teacher as conveyer of knowledge to giving students learning experiences that are as realistic as possible where they play a central role. Also, these approaches tend to emphasize fluency over accuracy to allow students to take risks in using more student-centered activities and to cooperate, rather than compete(Noemi2007) . The computer provides opportunity for students to be less dependent on a teacher and have more freedom to experiment on their own with natural language is natural or semi-natural settings.

\section{ROLECHANGESFORTEACHERSANDSTUDENTSTEACHERSSTUDENTS}

Although the integration of CALL into a foreign language program can lead to great anxiety among language teachers (Leigh2007), researchers consistently claim that CALL changes, sometimes radically, the role of the teacher but does not eliminate the need for a teacher altogether. Instead of handing down knowledge to students and being the center of students' attention, teachers become guides as they construct the activities students are to do and help them as students complete the assigned tasks. In other words, instead of being directly involved in students' constructions of the language, the teacher interacts with students primarily to facilitate difficulties in using the target language (grammar, vocabulary, etc.) as use the language to interact with the computer and/or other people(Noemi2007) ( Jonita 2002) Elimination of a strong teacher presence has been shown to lead to larger quantity and better quality of communication such as more fluidity, more use of complex sentences and more sharing of students' personal selves( Jonita 2002). However, teacher presence is still very important to students when doing CALL activities. Teachers should be familiar enough with the resources to be used to anticipate technical problems and limitations (Noemi2007). Students need the reassuring and motivating presence of a teacher in CALL environments. Not only are they needed during the initial learning curve, they are needed to conduct review sessions to reinforce what was learned. Encouraging students to participate and offering praise are deemed important by students. Most students report preferring to do work in a lab with a teacher's or tutor's presence rather than completely on their own( Jonita 2002).

Students, too, need to adjust their expectations of their participation in the class in order to use CALL effectively. Rather than passively absorbing information, learners must negotiate meaning and assimilate new information through interaction and collaboration with someone other than the teacher, be that person a classmate or someone outside of the classroom entirely. Learners must also learn to interpret new information and experiences on their own terms. However, because the use of technology redistributes teachers' and classmates' attentions, less-able students can become more active participants in the class because class interaction is not limited to that directed by the teacher( Jonita 2002). Moreover more shy students can feel free in their own students'-centered environment. This will raise their self-esteem and their knowledge will be improving.If students are performing collaborative project they will do their best to perform it within set time limits.

\section{USE OF CALL FOR THE FOUR SKILLS}

A number of studies have been done concerning how the use of CALL affects the development of language learners' four skills (listening, speaking, reading and writing). Most report significant gains in reading and listening and most CALL programs are geared toward these receptive skills because of the current state of computer technology. However, most reading and listening software is based on drills (Noemi2007). Gains in writing skills have not been as impressive as computers cannot assess this well( Jonita 2002). However, using current CALL technology, even with it current limitations, for the development of speaking abilities has gained much attention. There has been some success in using CALL, in particular computer-mediated communication, to help speaking skills closely linked to "communicative competence" (ability to engage in meaningful conversation in the target language) and provide controlled interactive speaking practice outside the classroom (Farzad \& Knodt 1998). Using chat has been shown to help students routinize certain often-used expressions to promote the development of automatic structure that help develop speaking skills. This is true even if the chat is purely textual. The use of videoconferencing give not only immediacy when communicating with a 
real person but also visual cues, such as facial expressions, making such communication moreauthentic (Jonita2002).

However, when it comes to using the computer not as a medium of communication (with other people) but as something to interact with verbally in a direct manner, the current computer technology's limitations are their clearest. Right now, there are two fairly successful applications of automatic speech recognition (ASR) (or speech processing technology) where the computer "understands" the spoken words of the learner. The first is pronunciation training. Learners read sentences on the screen and the computer gives feedback as to the accuracy of the utterance, usually in the form of visual sound waves (Farzad \& Knodt 1998). The second is software where the learner speaks commands for the computer to do. However, speakers in these programs are limited to predetermined texts so that the computer will "understand" them(Noemi2007).

\section{ADVANTAGESOFCALLMOTIVATION}

Generally speaking, the use of technology inside or outside the classroom tends to make the class more interesting. However, certain design issues affect just how interesting the particular tool creates motivation( Jonita 2002) . One way a program or activity can promote motivation in students is by personalizing information, for example by integrating the student's name or familiar contexts as part of the program or task. Others include having animate objects on the screen, providing practice activities that incorporate challenges and curiosity and providing a context (real-world or fantasy) that is not directly language-oriented.

For example, a study comparing students who used "CornerStone" (a language arts development program) showed a significant increase in learning (compared to students not using the program) between two classes of Englishimmersion middle-school students in language arts. This is because CornerStone incorporate personalized information and challenging and imaginative exercises in a fantasy context (Patrick 2003). Also, using a variety of multimedia components in one program or course has been shown to increase student interest andmotivation(Jonita2002). One quantifiable benefit to increased motivation is that students tend to spend more time on tasks when on the computer. More time is frequently cited as a factor in achievement ( Jonita 2002).

\section{ADAPTING LEARNING TO THE STUDENT}

Computers can give a new role to teaching materials. Without computers, students cannot really influence the linear progression of the class content but computers can adapt to the student (Noemi2007). Adapting to the student usually means that the student controls the pace of the learning but also means that students can make choices in what and how to learn, skipping unnecessary items or doing remedial work on difficult concepts. Such control makes students feel more competent in their learning (Patrick 2003). Students tend to prefer exercises where they have control over content, such as branching stories, adventures, puzzles or logic problems. With these, the computer has the role of providing attractive context for the use of language rather than directly providing the language the student needs(Noemi2007).

\section{AUTHENTICITY}

Authenticity" in language learning means the opportunity to interact in one or more of the four skills (reading, writing, listening, speaking) by using or producing texts meant for an audience in the target language, not the classroom. With real communication acts, rather than teacher-contrived ones, students feel empowered and less afraid to contact others. Students believe the learn faster and better with computer-mediated communication(Noemi2007) . Also, students learn more about culture in such an environment( Jonita 2002) . In networked computer environments, students have a conscious feeling of being members of a real community. In situations where all are learners of a foreign language, there is also a feeling of equality. In these situations students feel less stressed and more confident in a language learning situation, in part because surface errors do not matter so much. This works best with synchronous CMC (e.g. chats) as there is immediate feedback but email exchanges have been shown to provide most of the same benefits in motivation and student affect(Noemi2007). $+$

\section{THINKING SKILLS}

Use of computer technology in classrooms is generally reported to improve self-concept and mastery of basic skills, more student-centered learning and engagement in the learning process, more active processing resulting in higher-order thinking skills and better recall, gain confidence in directing their own learning. This is true for both language and non-language classrooms( Jonita 2002).

\section{PROBLEMS AND CRITICISMS OF CALL INSTRUCTION}

The impact of CALL in foreign language education has been modest(Farzad \& Knodt 1998) .Several reasons can be attributed to this. The first is the limitations of the technology, both in its ability and availability. First of all, there is the problem with cost(Mark 2008) and the simple availability of technological resources such 
as the Internet (either non-existent as can be the case in many developing country or lack of bandwidth, as can be the case just about anywhere) (Noemi2007). However, the limitations that current computer technology has can be problematic as well. While computer technology has improved greatly in the last three decades, demands placed on CALL have grown even more so. One major goal is to have computers with which students can have true, human-like interaction, esp. for speaking practice; however, the technology is far from that point. Not to mention that if the computer cannot evaluate a learner's speech exactly, it is almost no use at all (Farzad \& Knodt 1998) (Mark 2008).।

However, most of the problems that appear in the literature on CALL have more to do with teacher expectations and apprehensions about what computers can do for the language learner and teacher. Teachers and administrators tend to either think computers are worthless or even harmful, or can do far more than they are really capable of(Leigh2007).

Reluctance on part of teachers can come from lack of understanding and even fear of technology. Often CALL is not implemented unless it is required even if training is offered to teachers (Leigh2007). One reason for this is that from the 1960's to the 1980's, computer technology was limited mostly for the sciences, creating a real and psychological distance for language teaching (Ravichandran 2000). Language teachers can be more comfortable with textbooks because it is what they are used do, and there is the idea that the use of computers threatens traditional literacy skills since such are heavily tied to books (Ravichandran 2000) (Bollin 2003). These stem in part because there is a significant generation gap between teachers (many of whom did not grow up with computer)andstudents(whodidgrow up with them).

Also, teachers may resist because CALL activities can be more difficult to evaluate than more traditional exercises. For example, most Mexican teachers feel strongly that a completed fill-in textbook "proves" learning(Ravichandran 2000) . While students seem may be motivated by exercises like branching stories, adventures, puzzles or logic, these activities provide little in the way of systematic evaluation of progress (Noemi2007). Even teacher who may otherwise see benefits to CALL may be put off by the time and effort needed to implement it well. However, "seductive" the power of computing systems may be(Noemi2007), like with the introduction of the audio language lab in the 1960's, those who simply expect results by purchasing expensive equipment are likely to be disappointed(Mark 2008 . To begin with, there are the simple matters of sorting through the numerous resources that exist and getting students ready to use computer resources. With Internet sites alone, it can be very difficult to know where to begin, and if students are unfamiliar with the resource to be used, the teacher must take time to teach it(Noemi2007). Also, there is a lack of unified theoretical framework for designing and evaluating CALL systems as well as absence of conclusive empirical evidence for the pedagogical benefits of computers in language(Farzad \& Knodt 1998). Most teachers lack the time or training to create CALL-based assignments, leading to reliance on commercially-published sources, whether such are pedagogically sound or not (Mark 2008).

\section{Analyzing the results}

Thesamplebasedonsexfactorandtable(1)showsuchthing.

Table (1)

The distribution of the sample according to sex

\begin{tabular}{|r|r|r|}
\hline Gender & No. & $\%$ \\
\hline Male & 24 & 52.17 \\
\hline Female & 22 & 47.83 \\
\hline Total & 46 & 100 \\
\hline
\end{tabular}

\section{THE INTERNAL CONSISTENCY VALIDITY}

The internal consistency validity indicates the correlation of the degree of each item with the total average of he questionnaire. It also indicates the correlation of the average of each item with the total average. This validity was calculated by using Person Formula.Tables (2), (3) and (4) show the coefficient correlation of each item within its item is significant at levels $(0.01)$ and $(0.05)$.

Table (2) shows the correlation coefficient of each item with the whole questionnaire. According to the following tables, it can be concluded that the questionnaire is highly consistent and valid as a tool for the study 
Table (2 ) Correlation coefficient of the total degree of the teachers performance with its items

\begin{tabular}{|r|r|r||}
\hline Items & $\begin{array}{r}\text { Pearson } \\
\text { correlation }\end{array}$ & Sig. \\
\hline Listening & 0.354 & sig. at 0.05 \\
\hline Speaking & 0.576 & sig. at 0.01 \\
\hline Reading & 0.486 & sig. at 0.01 \\
\hline Priting & 0.324 & sig. at 0.05 \\
\hline Accent & 0.423 & sig. at 0.01 \\
\hline Vocabulary & 0.496 & sig. at 0.01 \\
\hline Composition & 0.409 & sig. at 0.01 \\
\hline Correlating teaching materials with students real experiences & 0.459 & sig. at 0.01 \\
\hline Moteresting the students & 0.391 & sig. at 0.01 \\
\hline Interesting in TEFl. & 0.627 & sig. at 0.05 \\
\hline Testing listening ability & 0.682 & sig. at 0.01 \\
\hline Testing speaking ability & 0.606 & sig. at 0.01 \\
\hline Testing reading ability & 0.652 & sig. at 0.01 \\
\hline Testing writing ability & 0.492 & sig. at 0.01 \\
\hline Cultural back ground & 0.479 & sig. at 0.01 \\
\hline Making teaching/ learning process more effective and enjoyable & 0.676 & sig. at 0.01 \\
\hline Mastering of grammar patterns in the two languages & 0.530 & sig. at 0.01 \\
\hline Communicating with learners & 0.397 & sig. at 0.01 \\
\hline Using A.V. aids & 0.538 & sig. at 0.01 \\
\hline \hline
\end{tabular}

"r" table value at (38) d f. at (0.05) sig. level equal 0.304

"r" table value at (38) $\mathrm{d}$ f. at (0.01) sig. level equal 0.393

Table (3) Correlation coefficient of the total degree of the learners' performance with it items

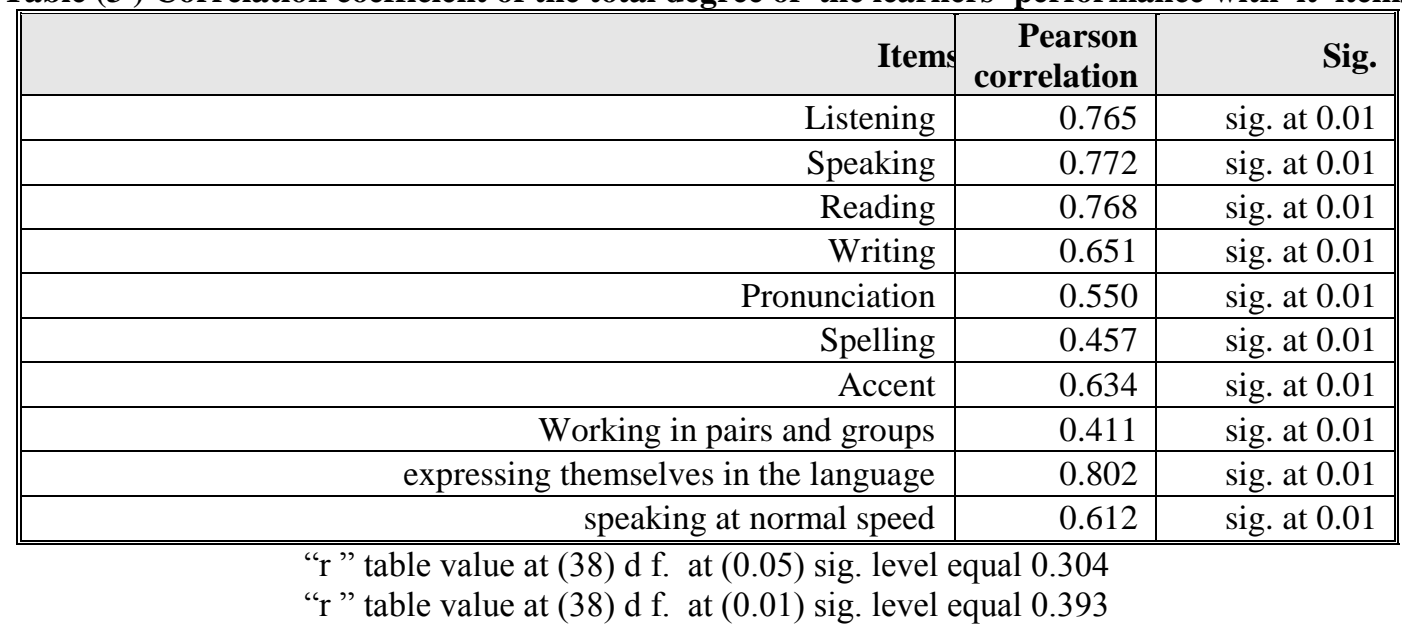

Table (4) Correlation coefficient of the total degree of the activity skill with it items

\begin{tabular}{|c|c|c|}
\hline Items & $\begin{array}{r}\text { Pearson } \\
\text { correlation }\end{array}$ & Sig. \\
\hline $\begin{array}{r}\text { Using computer - assisted language for teaching English } \\
\text { language }\end{array}$ & 0.488 & sig. at 0.01 \\
\hline Using a modern equipment and browser software & 0.314 & sig. at 0.05 \\
\hline Using computer games for teaching English language & 0.375 & sig. at 0.05 \\
\hline Using songs with call & 0.339 & sig. at 0.05 \\
\hline Interviews by computer (internet) & 0.394 & sig. at 0.01 \\
\hline Motion - picture film & 0.416 & sig. at 0.01 \\
\hline Wandering in the room & 0.452 & sig. at 0.01 \\
\hline Having the teacher good ability to use a computer & 0.538 & sig. at 0.01 \\
\hline
\end{tabular}


Using Computer Assisted Language Learning In Teaching

\begin{tabular}{|r|r|r||}
\hline Evaluating the computer skills of learners & 0.601 & sig. at 0.01 \\
\hline Familiarizing with basic internet technology & 0.311 & sig. at 0.05 \\
\hline Applying to behaviouristic approach & 0.332 & sig. at 0.05 \\
\hline Solving the problems of English language learning by call & 0.492 & sig. at 0.01 \\
\hline Applying to communicative approach & 0.383 & sig. at 0.05 \\
\hline Applying to integrative approach & 0.350 & sig. at 0.05 \\
\hline The suitability of the activities to the learner age, sex, ability and \\
interest
\end{tabular}

"r" table value at (38) d f. at (0.05) sig. level equal 0.304

"r" table value at (38) d f. at (0.01) sig. level equal 0.393

Reliability of the questionnaire

The reliability of the questionnaire was calculated by Alpha Cronbach and the Spilt- half techniques. Tables $5 \& 6$ show such thing.

Table (5) Reliability coefficient

\begin{tabular}{|c|c|c|}
\hline \multicolumn{3}{|l|}{ Alpha Cronbach Technique } \\
\hline Field & Total & Correlation \\
\hline First & 21 & 0.851 \\
\hline Second & 10 & 0.802 \\
\hline Third & 15 & 0.524 \\
\hline
\end{tabular}

Table (5) proves that the questionnaire is reliable.

Correlation between two parts (even X odd) and modify by Spearman brown:

Table (6)

\begin{tabular}{|c|c|c|c|}
\hline SPILT -HALF TECHNIQUE & & & \\
\hline SCOPE & TOTAL & BEFORE & AFTER \\
\hline First & 21 & 0.611 & 0.616 \\
\hline Second & 10 & 0.394 & 0.565 \\
\hline Third & 15 & 0.675 & 0.676 \\
\hline
\end{tabular}

Table (6) proves that the questionnaire is reliable.

The questionnaire can be applied in the study.Answering the first question: How do teachers evaluate their performance in English language skills?To answer such question the researcher used the frequencies, the sum of responses, means, std. deviation and the \% weight and rank of each item from the questionnaire , table (7) shows such thing:

Table (7) frequencies, the sum of responses, means, std. deviation . And the \% weight and rank of each teacher's performance

\begin{tabular}{|l|l|l|l|l|l|l||}
\hline No. & Item & Sum & Mean & $\begin{array}{l}\text { Std. } \\
\text { Deviati } \\
\text { on }\end{array}$ & $\begin{array}{l}\text { \% } \\
\text { weight }\end{array}$ & $\begin{array}{l}\text { Ran } \\
\text { k }\end{array}$ \\
\hline 1 & Listening & 486 & 3.522 & 0.653 & 88.04 & 1 \\
\hline 2 & Speaking & 450 & 3.261 & 0.608 & 81.52 & 3 \\
\hline 3 & Reading & 468 & 3.391 & 0.572 & 84.78 & 2 \\
\hline 4 & Writing & 438 & 3.174 & 0.819 & 79.35 & 5 \\
\hline 5 & Pronunciation & 444 & 3.217 & 0.722 & 80.43 & 4 \\
\hline 6 & Accent & 390 & 2.826 & 1.053 & 70.65 & 16 \\
\hline 7 & Vocabulary & 408 & 2.957 & 0.693 & 73.91 & 11 \\
\hline 8 & Composition & 372 & 2.696 & 0.623 & 67.39 & 18 \\
\hline 9 & $\begin{array}{l}\text { Correlating teaching materials with } \\
\text { students real experiences }\end{array}$ & 360 & 2.609 & 0.875 & 65.22 & 19 \\
\hline 10 & Moteresting the students & 414 & 3.000 & 0.725 & 75.00 & 9 \\
\hline 11 & Interesting in TEFL & 402 & 2.913 & 0.884 & 72.83 & 13 \\
\hline
\end{tabular}


Using Computer Assisted Language Learning In Teaching

\begin{tabular}{||l|l|l|l|l|l|l||}
\hline 12 & testing listening ability & 396 & 2.870 & 0.743 & 71.74 & 15 \\
\hline 13 & testing speaking ability & 402 & 2.913 & 0.778 & 72.83 & 14 \\
\hline 14 & testing reading ability & 420 & 3.043 & 0.693 & 76.09 & 7 \\
\hline 15 & testing writing ability & 420 & 3.043 & 0.693 & 76.09 & 8 \\
\hline 16 & Cultural back ground & 360 & 2.609 & 0.875 & 65.22 & 20 \\
\hline 17 & Mastering of the mother tongue & 432 & 3.130 & 0.743 & 78.26 & 6 \\
\hline 18 & $\begin{array}{l}\text { Making teaching/ learning process } \\
\text { more effective and enjoyable }\end{array}$ & 414 & 3.000 & 0.888 & 75.00 & 10 \\
\hline 19 & $\begin{array}{l}\text { Mastering of grammar patterns in the } \\
\text { two languages }\end{array}$ & 408 & 2.957 & 0.862 & 73.91 & 12 \\
\hline 20 & Communicating with learners & 384 & 2.783 & 0.934 & 69.57 & 17 \\
\hline 21 & Using A.V .aids & 348 & 2.522 & 1.020 & 63.04 & 21 \\
\hline
\end{tabular}

From table (7) we can notice that the most two difficulties are:

- $\quad$ No (1) " Listening "occupied the first rank with percentage(88.04\%).

- $\quad$ No(3)"Reading" occupied the second rank with percentage (84.78\%).

And the least are:

- $\quad$ No(16)" Cultural back ground " occupied the twentieth rank with percentage(65.22\%).

- $\quad$ No (21) " Using A.V. aids " occupied the twenty first rank with percentage $(63.04 \%)$.

- Answering the second Question: How do teachers evaluate the learners standard in English Language skills ?To answer this question the researcher used the frequencies, the sum of responses, means, std. deviation and the $\%$ weight and rank of each item from the questionnaire, table (8) shows this:

Table (8) frequencies, the sum of responses, means, std. deviation . And the \% weight and rank of each learners' performance

\begin{tabular}{|l|l|l|l|l|l|l||}
\hline No. & Item & Sum & Mean & $\begin{array}{l}\text { Std. } \\
\text { Deviati } \\
\text { on }\end{array}$ & $\begin{array}{l}\text { \% } \\
\text { weight }\end{array}$ & $\begin{array}{l}\text { ran } \\
\mathbf{k}\end{array}$ \\
\hline 1 & Listening & 390 & 2.826 & 0.704 & 70.65 & 3 \\
\hline 2 & Speaking & 390 & 2.826 & 0.704 & 70.65 & 4 \\
\hline 3 & Reading & 396 & 2.870 & 0.614 & 71.74 & 2 \\
\hline 4 & Writing & 372 & 2.696 & 0.807 & 67.39 & 5 \\
\hline 5 & Pronunciation & 324 & 2.348 & 0.701 & 58.70 & 9 \\
\hline 6 & Spelling & 330 & 2.391 & 0.572 & 59.78 & 7 \\
\hline 7 & Accent & 306 & 2.217 & 0.886 & 55.43 & 10 \\
\hline 8 & Working in pairs and groups & 396 & 2.870 & 0.853 & 71.74 & 1 \\
\hline 9 & Expressing themselves in the language & 330 & 2.391 & 0.875 & 59.78 & 6 \\
\hline 10 & Speaking at normal speed & 330 & 2.391 & 0.970 & 59.78 & 8 \\
\hline
\end{tabular}

Table (8) shows the most two difficulties are:

- $\quad$ No (8) " working in pairs and groups "occupied the first rank with percentage( $71.74 \%$ ).

- $\quad$ No(3)"The Reading" occupied the second rank with percentage (71.74\%).And the least are:

- $\quad$ No (5) "pronunciation" occupied the ninth rank with percentage (58.70\%).

- $\quad$ No (7) "Accent "occupied the ten rank with percentage $(55.43 \%)$.

To conclude the results, the researcher used, the sum of responses, means, std. deviation and the $\%$ weight and rank of each field from the questionnaire and table (9) shows this:

Table (9) sum of responses, means, std. deviation . And the \% weight and rank of each field from the questionnaire 


\begin{tabular}{||r|l|l|l|l|l|r||}
\hline Field & $\begin{array}{l}\text { No. of } \\
\text { items }\end{array}$ & Sum & Mean & $\begin{array}{l}\text { Std. } \\
\text { Deviation }\end{array}$ & $\begin{array}{l}\text { \% } \\
\text { weight }\end{array}$ & Rank \\
\hline First & 138 & 8616 & 62.435 & 7.924 & 74.33 & 1 \\
\hline Second & 138 & 3564 & 25.826 & 4.572 & 64.57 & 2 \\
\hline TOTAL & 138 & 12180 & 88.261 & 10.725 & 71.18 & \\
\hline
\end{tabular}

- From table (9) we can notice that the first field occupied the first rank with percentage (74.33\%), the second field occupied the second rank with percentage $(64.57 \%)$, and we can notice the total degree is $(71.18 \%)$. Answering the third Question: How are the effectiveness of activity skills of English language learning ?

To answer this question the researcher used the frequencies, the sum of responses, means, std. deviation , and the \% weight and rank of each item from the questionnaire table (10) shows this:

Table (10) frequencies, the sum of responses, means, std. deviation . And the \% weight and rank of each activity skill and this effectiveness

\begin{tabular}{||l|l|l|l|l|l|l|l|l|l||}
\hline No. & Activity skills & \multicolumn{3}{|l|}{$\begin{array}{l}\text { Will be most Will be of } \\
\text { effective } \\
\text { some effect }\end{array}$} \\
effect
\end{tabular}

Answering the fourth question :Are there any statistical significant differences at $(\propto \leq 0.05)$ in the level of application of activity skills in Gaza City based on gender suggestion?

To answer this question the researcher used T.test, table (11) shows this:

Table (11) means, std. deviation t. value, and sig. level to know the difference between male and female \begin{tabular}{|l|l|l|l|l|l|l|l|}
\hline Field & gender & $\mathbf{N}$ & Mean & Std. Deviation & $\mathbf{T}$ value & Sig. level \\
\hline
\end{tabular} 


\begin{tabular}{|c|c|c|c|c|c|c|c|}
\hline Field & & gender & $\mathbf{N}$ & Mean & Std. Deviation & T value & Sig. level \\
\hline & \multirow[t]{2}{*}{ first } & male & 72 & 58.250 & 7.671 & \multirow{2}{*}{7.753} & \multirow{2}{*}{ sig. at 0.01} \\
\hline & & female & 66 & 67.000 & 5.245 & & \\
\hline & \multirow[t]{2}{*}{ second } & male & 72 & 24.167 & 5.198 & \multirow[t]{2}{*}{4.798} & \multirow{2}{*}{ sig. at 0.01} \\
\hline & & female & 66 & 27.636 & 2.859 & & \\
\hline \multirow{2}{*}{\multicolumn{2}{|c|}{ TOTAL }} & male & 72 & 82.417 & 11.689 & \multirow[t]{2}{*}{8.116} & \multirow{2}{*}{ sig. at 0.01} \\
\hline & & female & 66 & 94.636 & 3.752 & & \\
\hline
\end{tabular}

“t” table value at (44) d f. at (0.05) sig. level equal 2.02

"t" table value at (44) $\mathrm{d}$ f. at (0.01) sig. level equal 2.70

Upon computing T. value, we found that it is more than the critical $(\alpha \leq 0.05)$, in first and second and total degree field, the difference is in favor of female.

\section{RECOMMENDATIONS}

On viewing and considering the results of such research, the researcher adopted and suggested some recommendations in order to develope students' language skills by using computer:-

1-The Ministry of Education and UNRAWA should supply schools with computers and accessories .

2-The Ministry of Education should and UNRAWA should hold and conclude training courses for teachers to improve their ability and to acquaint with the using of computer effectively and perfectly.

3-Constructing new schools to avoid crowded classes.

4-Teachers should be familiar with the followings :-

a)Using computers effectively and perfectly.

b)Using modern computer equipment and browser software.

c)Using the basic internet technology to anticipate potential problems.

5-Teachers should participate with each other to solve any problems regarding computers.

6-Teachers should use suitable and modern programs for teaching process by using computers.

7-Encouraging the teachers to use the computers in teaching English Language process.

8-Enhancing the role of computer in English Language teaching .

9-The Ministry of Education and concerned parties should supply the schools with computer lab.

10-The Ministry of Education and concerned parties should establish and construct underground construction to be suitable for computer installation.

11-Encourging, persuading and promoting male teachers to use computers in their English teaching process.

12-Carrying out more researches about using computers in teaching English Language.

\section{REFERENCES}

[1] Alcaraz, A.(1997)Taller,II Jornals de Estudios Ingleses, Jain Universidad de Jain. 195-227

[2] CALL (computer assisted language learning) Guide to Good Practice 3. Davies Graham. Retrieved on 2007-12-01.

[3] Computer-assisted language learning: Increase of freedom of submission to machines? (Domingo Noemi). Retrieved on 2007-12-10.

[4] Davies, G.(1986)- Authoring CALL Coursware: A Practical Approach , in LEECH, G. CANDLIN, N.L. Computers in English Teaching and Research London: Longman,12 -29

[5] Higgins J. The Computer and Grammar Teaching, in LEECH, G and CANDLIN,N.L. Computer in English Language Teaching and Research ,London: Longman,31-45.

[6] Higgins J. Reading ,Writing, and Pointing: Communicating with Computer ,in LEECH, G and CANDLIN,N.L. Computer in English Language Teaching and Research ,London: Longman,47-55.

[7] Lewis, R(1986) Computer and Language Teaching, in LEECH, G and CANDLIN,N.L. Computer in English Language Teaching and Research ,London: Longman,55-59.

[8] Philip, M.(1999) CALL in it Education Context ,in LEECH, G and CANDLIN,N.L. Computer in English Language Teaching and Research ,London: Longman,2-10.

[9] Petrson, M.(1999) World Wide Web Resources for the ESP Practitioners, English for Specific Purposes 18: s75-s 80

[10] Skinner,B. and Austin ,R. Conferencing- Does it motivate EFL students ? ELT Journal 53/4: 270-279.

[11] Role Playing Games and the English as a Foreign Language Classroom (journal article). Retrieved on 200711-12.

[12] MOO: The virtual classroom (Journal article). Retrieved on 2007-12-01.

[13] Dorveaux, Xavier. "Apprendre une langue dans un monde virtuel", Le Monde, 2007-07-15. Retrieved on 2007-07-15.

[14] Computer Assisted Language Learning: an Introduction. Warschauer Mark. Retrieved on 2008-04-11. 
[15] Ten Hacken, Pius (May 2003). "Computer-assisted language learning and the revolution in computational linguistics". Linguistik online 17. Retrieved on 2007-12-11.

[16] Ehsani, Farzad; Eva Knodt (July 1998). "Speech technology in computer-aided language learning: Strenghts and limitations of a new CALL paradigm". Language Learning and Technology 2 (1): 45-60. Retrieved on 2007-12-02.

[17] Stepp-Greany, Jonita (January 2002). "Students perceptions on language learning in a technological environment: Implications for the new millennium". Language Learning and Technology. Retrieved on 2007-12-15.

[18] Mitchell, R; F. Myles (1998). Second Language Learning Theories. London: Arnold.

[19] Thelmadatter, Leigh (July/Sept 2007). "The Computers Are Coming ... Are Here!". TESOL Greece Newsletter 95. Retrieved on 2007-12-16.

[20] Traynor, Patrick (July 2003). "Effects of computer-assisted instruction on different learners". Journal of Instructional Psychology. Retrieved on 2007-12-015.

[21] Ravichandran, T (2000). "Computer-assisted language learning (CALL) in the perspective of the interactive approach: Advantages and apprehensions". Retrieved on 2007-11-15.

[22] Bollin, G.G. (Mar/Apr 2003). "The Realities of Middle School for Mexican Children". The Clearing House 76 (4): 198. Retrieved on 2007-11-28.

[23] Ahmed K et al.(1985) Computers, Language Learning and Language Teaching CUP: Cambridge.

[24] Brett P.(1998) "An Intutive, Theoretical and Empirical Perspective on the Effwctiveness Question for Multimedia" in Cameron K (Ed) Multimedia CALL: Theory and Practice Exeter: Elm Bank.

[25] Hubbard P.(1987) Language Teaching Approaches of CALL Software and Design Implications" In Smith F Modern Media in Foreign Language Education: Theory and Implementation Illinois :NTC

[26] Jones A \& Mercer N.(1993)" Theories of Learning and Information Technology in Scrimshaw P. (ED) Language, Classroom and Computers.

[27] Jones C \& Fortescue S.(1987) Using Computers in The Language Classroom London: Longman.

[28] Kenning M M \& Kenning M J (1990) Computers and Language Learning: Current Theory and Practice Chichester UK:Ellis Horwood .

[29] Levy M.(1997) Computer Assisted Language Learning: Context and Conceptualization Oxford: Claredon Press

[30] Taylor R P (1980) The Computer in the School : Tutor, Tool, Tutee Teacher's College Press: Columbia University , New York.

[31] Underwood J (1984) Linguistics, Computers and the Language Teacher Rowley, Mass, Newbury House.

[32] Warschauer \& Healey D. (1998) Computer and Language Learning: An Overview in Language Teaching, Vol, 31, 57-71.

[33] Lourdes Ortega (1997) Processes and Outcomes in Networked Classroom Interaction: Defining the Research Agenda For L2 Computer-Assisted Classroom Discussion, Vol.1, No.1 July 1997,pp 82-93.

[34] Kiraki Spanou (2001) Computer-Assisted Language Learning; A Story that goes Long back.

[35] 35-Liu Meng, Huo Hong, (2007) Computers Assisted Language Learning (CALL) In China: Some Common Concerns., Vol.5 No.1 (Serial N0 40)

[36] Computer-Assisted Language Learning from Wikpedia, the free Encyclopedia. 